\title{
Knowledge, Attitudes and Practices (K.A.P) of Pharmacy Pharmacists of the Department of Dakar in the Care of Diabetics
}

\author{
Diallo Ibrahima Mane*, Diédhiou Demba, Sow Djiby, Ndour Michel Assane, Aissatou Camara, \\ Ahmet Limane Barrage, M. Ka-Cissé, Sarr Anna, Ndour-Mbaye Maimouna \\ Clinique Médicale II, Centre Hospitalier Abass Ndao, UCAD, Dakar, Senegal \\ Email: *ibrahimamanediallo@hotmail.fr, dembadiedhiou@gmail.com,drdjiby@yahoo.fr, michelassanendour@yahoo.fr, \\ aissatoucamara1989@yahoo.com, limaneab@gmail.com, marikacisse@gmail.com, annasarr@orange.sn, mbayester@gmail.com
}

How to cite this paper: Mane, D.I., Demba, D., Djiby, S., Assane, N.M., Camara, A., Barrage, A.L., Ka-Cissé, M., Anna, S. and Maimouna, N.-M. (2019) Knowledge, Attitudes and Practices (K.A.P) of Pharmacy Pharmacists of the Department of Dakar in the Care of Diabetics. Journal of Diabetes Mellitus, 9, 113-125.

https://doi.org/10.4236/jdm.2019.93011

Received: June 18, 2019

Accepted: August 19, 2019

Published: August 22, 2019

Copyright $\odot 2019$ by author(s) and Scientific Research Publishing Inc. This work is licensed under the Creative Commons Attribution International License (CC BY 4.0).

http://creativecommons.org/licenses/by/4.0/

\begin{abstract}
Aim: To evaluate the attitude practice and knowledge of pharmacists in the management of diabetes in the department of Dakar. Methodology: Cross-sectional study, conducted from 01 March to 30 September 2017 including all pharmacists in the Dakar region who agreed to participate in the survey. Data was collected through a pre-established questionnaire. Results: A total of 144 pharmacists were included in the study, representing a participation rate of $87.58 \%$. The average age was 33.90 years, with a sex ratio of 1.69. Pharmacists were single in $50.88 \%$ of cases, and a minimum experience of 5 years was found in $64.03 \%$ of cases. Pharmacist assistants accounted for $57.9 \%$ of our study population. The assessment of knowledge based on 16 items shows an average score of 9.02. The level of knowledge was low to insufficient in $37.21 \%$ of cases, average in $(50 \%)$ half of cases and good for (13.16\%). Less than half $(34.21 \%)$ of pharmacists had received training and the average date of last training was $33.76 \pm 24.6$ months. Training was provided by medical representatives and academics in $66.66 \%$ and $26.67 \%$ respectively. The most felt positive feelings were respectively the need for help, the compassion in respectively $98.42 \%, 42.11 \%$. Feelings felt and simultaneously cited were: need for help and compassion in more than $40 \%$ of respondents. Only $29 \%$ of pharmacists did not have a lot of difficulty with patient questions and the only reason was the lack of awareness $(84.68 \%)$ of patients about their disease. Screening for diabetes by capillary blood glucose was performed by $57 \%$ of pharmacists. Dietary advice $(76.15 \%)$ and referral to the hospital (94.41\%) were the most common practices in case of blood sugar disruption. The dialogue with patients was impossible in $22.81 \%$ of pharmacists and the main reasons given were lack of time (53.85\%) and lack
\end{abstract}


of knowledge (34.62\%). The method of delivery of insulin was done on: medical prescription $(98.25 \%)$, presentation of the box $(69.30 \%)$, on request of the patient $(54.39 \%)$. Only one pharmacist recognized advising insulin (0.88\%). The delivery of oral antidiabetic agents was: on medical prescription (96.49\%), presentation of the box $(67.54 \%)$, at the request of the patient $(52.63 \%)$. The good level of knowledge was more found in the subjects after 40 years $(p=$ $0.69)$, the female sex $(p=0.84)$, the assistants and holders $(p=0.24)$, after 5 years of professional experience $(p=0.13)$. Conclusion: Despite the lack of knowledge of pharmacists, attitudes and practices are considered satisfactory in the management of diabetics. Continuing medical education sessions could strengthen knowledge and consolidate the attitudes and practices of community pharmacists.

\section{Keywords}

Management, Pharmacist, Diabetes, Dakar

\section{Introduction}

Diabetes mellitus is a chronic disease that develops when blood glucose levels rise permanently beyond a threshold secondary to: failure to produce or use insulin [1]. The prevalence of diabetes worldwide was $8.8 \%$ in 2017 , and $79 \%$ lived in low- and middle-income countries. It is in regions with a low to medium-income economy that will experience the largest increase. The economic impact of diabetes is significant. In fact, $\$ 727$ billion was spent annually by diabetics on health care in worldwide in 2017 [2]. Diabetes mortality in 2017 was estimated at 4 million people, which corresponded to one death every eight seconds [2]. This was down from the 2015 mortality rate of 5 million people [3]. Diabetes accounts for $10.7 \%$ of global mortality from all causes. Associated with the 3 major non-communicable diseases (NCDs) that are: cardiovascular diseases, chronic respiratory diseases, and cancers, diabetes was responsible for more than $80 \%$ of all premature deaths from NCDs [2]. This percentage of deaths was higher in Africa and the Middle East [2]. World Health Organization (WHO) predicts that by 2030 , diabetes will be the seventh leading cause of death worldwide [4].

In Senegal, the 2015 STEP survey revealed a prevalence of diabetes of $3.4 \%$ [5].

In developing countries, the difficulty of access to health facilities means that patients take alternative routes to health care: traders, pharmacists, and even speculations of other patients with the same pathologies, and close relations with health workers. In Senegal, the pharmacist plays an important role in the health system in the management of diabetes. It is for the most part the first local health staff contacted for: counseling, screening, or for management of an illness. The reasons that explain this phenomenon are: the proximity of the pharmacist, the 
modest standard of living of the general population, the fear, the insufficiency of the health structures, but also the deficit of qualified personnel in the management of the diabetes.

This prompted us to carry out this work, with the main objective of evaluating the knowledge, attitudes, and practices of pharmacy pharmacists of the Dakar Department in the management of diabetics.

The secondary objectives were:

- Describe the sociodemographic characteristics of dispensing pharmacists in the department of Dakar;

- Evaluate their level of knowledge about diabetes;

- Determine the attitudes and practices of pharmacy pharmacists of the Dakar Department in the management of diabetes;

- Identify the sources of knowledge of pharmacists on diabetes.

\section{Material and Method}

The survey was conducted in the department of Dakar which occupies $0.28 \%$ of the national territory. The department had 1,146,053 inhabitants for an area of $550 \mathrm{~km}^{2}$.

In 2014, the region had 589 health structures of all types, 33\% of which were located in the department of Dakar. It also housed 524 pharmacies. In the department, we counted 229 pharmacies [6]. At the social level, the Dakar Department accounted for $44 \%$ of households in the region as a whole.

\subsection{Type of Study and Period of Study}

Our study was observational, cross-sectional descriptive for analytical purposes conducted from March 1st to September 30th, 2017.

\subsection{Study Population}

The study population consisted of pharmacists holding a doctorate in pharmacy and pharmacy students at the end of their training practicing in the pharmacies of the department of Dakar.

\subsection{Sample Size and Procedure}

The sample size was estimated according to the SCHWARTZ formula: $n=z^{2} \cdot p \cdot q / d^{2}, z=1.96$ for a margin of error of $5 \%$. Since $\mathrm{p}$ is unknown, we assumed that the proportion of correct answers for each question will be $50 \%$ for a margin of error of 5\%, at the confidence level $\alpha=5 \%$. Thus, the target population was $n=384$ pharmacists for a total of 229 pharmacies counted [6]. However, the size $N$ of the source population is less than 10.000 an adjustment has been made thanks to the formula $n^{\prime}=n /(1+n / N)$ which gives us an adjusted sample size of $n^{\prime}=144$.

The department of Dakar counted 19 district municipalities. However, for reasons of feasibility, we conducted our study in 16 communes (Table 1). 
Table 1. Distribution of pharmacies to be included in each district municipality, Dakar, Senegal, $2017\left(n^{\prime}=144\right)$.

\begin{tabular}{|c|c|c|c|}
\hline Borough municipality & $\begin{array}{l}\text { Number of existing } \\
\text { pharmacies }\left(N_{i}\right)\end{array}$ & $\begin{array}{c}\% \\
\left(N_{i} / 229\right)\end{array}$ & $\begin{array}{l}\text { Number of pharmacies to } \\
\text { include } n_{i}^{\prime}\left(n_{i}^{\prime}=n^{\prime} * N_{i} / 229\right)\end{array}$ \\
\hline Dakar Plateau & 37 & 16.1 & 23 \\
\hline Parcelles assainies & 29 & 12.6 & 18 \\
\hline Grand Yoff & 26 & 11.3 & 16 \\
\hline Cambèrène & 05 & 2.1 & 3 \\
\hline Patte d'oie & 02 & 0.8 & 2 \\
\hline Mermoz-Sacre cœur & 15 & 6.5 & 10 \\
\hline Fann-Amitié-Point E & 10 & 4.3 & 6 \\
\hline Ouakam & 13 & 5.6 & 8 \\
\hline Gueule tapée-Fass-Colobane & 16 & 6.9 & 10 \\
\hline Sicap liberté & 10 & 4.3 & 6 \\
\hline Dieuppeul-Derkle & 09 & 3.9 & 6 \\
\hline Grand Dakar & 17 & 7.4 & 11 \\
\hline HLM & 09 & 4.3 & 6 \\
\hline Medina-Centenaire-Gibraltar & 18 & 7.8 & 11 \\
\hline Yoff & 10 & 4.3 & 6 \\
\hline Ngor & 03 & 1.3 & 2 \\
\hline Total & 229 & 100 & 144 \\
\hline
\end{tabular}

We conducted a stratified proportional allocation survey. The strata were the borough communes. In each of them, we conducted a raffle of pharmacies using the ALEA function of the Microsoft Excel 2010 software that generated random numbers. These were ranked in descending order. Each number corresponded to a pharmacy. Only the first ones that corresponded to the number to be included in each stratum were retained.

\subsubsection{Inclusion Criteria}

- Have a doctorate in pharmacy or student who has validated the second cycle of pharmaceutical studies.

- Being present on the day of the survey.

- To have agreed to participate in the study.

\subsubsection{Criteria of Non-Inclusion}

Refusal to participate in the survey or absent on the day of the survey.

\subsection{Operational Definition of Concepts [7]}

Knowledge: it was defined as a set of known things, knowledge, "science".

Attitude is defined as a state of mind of a subject or a group vis-à-vis an object, an action, an individual or a group; it's someone's knowing how to be. Ac- 
cording to Thurstone, the attitude is a positive or negative feeling towards the object. Gordon Allport considers attitude as a mental and neuropsychological state of preparation for action, organized as a result of experience and which exerts a dynamic influence on the behavior of the individual with respect to all objects and all related situations.

Practices are behaviors, observable actions of an individual in response to a stimulus. However, the practice conceals a specific knowledge that is different from the theory that is supposed to found or account for it.

Criteres de diagnostic de Americain Diabetes Association and the European Association Society of Diabetes (ADA-EASD): Blood glucose (on venous plas$\mathrm{ma}$ ) fasting (for at least eight hours) greater than or equal to $1.26 \mathrm{~g} / \mathrm{l}(7.0$ $\mathrm{mmol} / \mathrm{l}$ ); Blood glucose (venous plasma) two hours after ingestion of $75 \mathrm{~g}$ of glucose (OGTT test) greater than or equal to $2.00 \mathrm{~g} / \mathrm{l}(11.1 \mathrm{mmol} / \mathrm{l})$, Presence of symptoms of diabetes (polyuria, polydipsia, slimming) and blood glucose (on venous plasma) measured at any time, greater than or equal to $2.00 \mathrm{~g} / \mathrm{l}(11.1$ $\mathrm{mmol} / \mathrm{l})$, and $\mathrm{HbAlc}$ greater than or equal to $6.5 \%$ (48 $\mathrm{mmol} / \mathrm{mol})$ using a measurement method certified by the National Glycohemoglobin Standardization Program (NGSP) and standardized to the Diabetes Control and Complications Trial (DCCT) standards.

\subsection{Tool and Collection Techniques}

The collection tool used was a questionnaire with 25 questions spread across five (05) sections. this questionnaire approved by the ethics committee is based on the knowledge attitudes and practices (KAP) survey style and adapted to the work context and subject. The first was related to socio-demographic characteristics [8].

The second and third sections were respectively devoted to knowledge and sources of information.

The fourth was to collect information about attitudes. Finally, the fifth section collected data on practices. The questionnaire was previously tested with ten (10) pharmacists. These were not included in the study. The pre-test allowed us to readjust and validate the questionnaire.

Data collection was done by a student in a pharmacy thesis year. The interview was straightforward and the average duration of the survey was approximately 30 minutes. The interviewer was provided with her student card to facilitate identification and participation of the pharmacist in the study. The data collected allowed us to obtain the following parameters:

Socio demography: age, sex, marital status, number of years of practice and professional status.

Knowledge data related to diagnostic criteria, clinical signs, type of diabetes, complications, treatment, pharmacology of oral antidiabetic drugs (contraindications, drug interactions and side effects) and the modalities of delivery and substitution of diabetes medications. 
As for sources of knowledge, the information collected was the date of the last diabetes training, followed by the pharmacist, the training institution, and the availability of a diabetes document.

The data on attitudes concerned the feeling experienced by a diabetic, the difficulty of answering the questions posed by diabetic patients, the opinion of the pharmacist on the need to communicate with the patient's entourage, the pharmacist's perception of knowledge of diabetes and its motivation to learn about one aspect of diabetes.

Finally, the data on the practices were the availability of a service of detection of the diabetes in pharmacy, the measured parameters, the reaction towards a suspect subject of diabetes, the practice of discussion with the diabetic patients, the barriers preventing this discussion, the mode of delivery of insulins and oral antidiabetic drugs.

The level of knowledge was quantified. The correct answer to a question was noted a point. A wrong answer was worth zero. The minimum expected score was 0 while the maximum was 14 . For multiple-choice questions, score 1 was assigned to each pharmacist who cited at least 2 correct items (types of diabetes, clinical signs and contraindications) or at least 23 right items (complications, drug interactions and side effects).

The knowledge was classified into four levels that grew according to a method corresponding to the health staff:

- Bad: less than $50 \%$ of correct answers;

- Insufficient: less than $65 \%$ of correct answers;

- Average: less than $85 \%$ of correct answers;

- Good: over $85 \%$ of correct answers.

The statistical analysis consisted of two parts. The first was descriptive and allowed the qualitative variables to be expressed as a percentage. Quantitative variables were summarized by mean, standard deviation, extremes, mode, median, first interquartile, and third interquartile. The second part was analytical and consisted in identifying the sociodemographic characteristics associated with the good level of knowledge. The Chi-square test or Fisher's exact test was used. The dependent variable was the level of knowledge. The independent variables were age, sex, marital status, years of practice and employment status. An association was significant if the $\mathrm{p}$-value is less than 0.05 . The data was entered and analyzed using the Epi Info software.

Ethical considerations: A newsletter was sent to each pharmacist. An oral consent from each pharmacist was collected after informing of the ethics committee's approval and explaining the objectives and expected results of the study. The data was treated anonymously and confidentially.

\section{Results}

A total of 144 pharmacists were included. Among them 19 had refused to participate, a participation rate of $87.58 \%$. After the survey, 11 pharmacists had not 
reported their age. Thus, 114 cards were taken into account in the final analysis.

\subsection{Descriptive Part}

\subsubsection{Sociodemographic Characteristics}

The average age of community pharmacists was 33.90 years with extremes of 22 to 62 years. The 20 - 29 age group was predominant (45.61\%) and the sex ratio was 1.69. Single persons accounted for 50.88\% $(n=58)$ and divorced women $2.63 \%(n=3)$. The number of years of practice of pharmacists between 2 and 5 years were $33.33 \%$, and those under 2 years of $30.70 \%$. Most pharmacists were pharmacist assistants (57.9\%), $\mathrm{PhD} /$ trainee assistant (25.4\%).

\subsubsection{Knowledge about Diabetes}

All pharmacists claimed to know diabetes. The diagnosis of diabetes by criteria Americain Diabetes Association and the European Association Society of Diabetes (ADA-EASD) on fasting glucose was found by $78.95 \%$ of pharmacists, and about $33.33 \%$ of them knew the diagnostic criteria with blood sugar at random. Diabetes type 1 and 2 were cited by $99.12 \%$ of pharmacists and gestational diabetes by $58.77 \%$ of pharmacists. The clinical signs of diabetes were known by all pharmacists. The most cited signs were polyuria (94.49\%), polydipsia (86.84\%) and polyphagia (82.46\%) respectively.

Most pharmacists $(97.37 \%)$ claimed to know the complications of diabetes and $88.6 \%$ had at least three diabetes complications. Retinopathy, diabetic foot and nephropathy were cited by $84.68 \%, 78.38 \%$ and $75.68 \%$ of pharmacists, respectively.

Systematic insulin therapy in type 1 diabetes was known by $86.4 \%$ of pharmacists and the subcutaneous route of administration was cited by $55.5 \%$ of pharmacists compared to $37.37 \%$ for other routes (intramuscular and intrader$\mathrm{mal}$ ), the lack of knowledge of the insulin administration route was found in 7.07\% of pharmacists.

Insulin therapy in type 2 diabetes was considered transient by $67.01 \%$ of pharmacists and definitive by $17.53 \%$ of cases. The use of oral antidiabetic agents in the treatment of type 2 diabetics was cited by $80.70 \%$ of pharmacists. The contraindications of oral anti diabetic OAD were known by 77 pharmacists (67.54\%) and 37 pharmacists (32.46\%) had no idea. The most frequently reported contraindications were, respectively, hypersensitivity to the molecule (77.92\%) and severe renal insufficiency (63.64\%). The side effects were known by 63 pharmacists (55.26\%) and the most cited were, nausea (85.71\%), vomiting (70.03\%), diarrhea $(52.38 \%)$ and abdominal pain (50.79\%). Pharmacists who were able to cite 3 side effects were 40 (35.06\%).

The substitution of drugs is a possibility and a reality, in our study, 62 (54.39\%) pharmacists had stated that it was necessary to keep the same doses and the same frequency of injection in case of substitution with another insulin. Only $13.16 \%$ (15 pharmacists) had a good knowledge of how to substitute one insulin for another. 
For oral antidiabetic drugs the substitution was approved by 89 (78.07\%) community pharmacists, the most commonly cited substitution modalities were the same molecule and the same dosage (Table 2).

In total the score was between 0 and 14. In our study, the average knowledge score was 9.02 with a standard deviation of 2.4. The mode was 9. The first and third interquartiles were 8 and 11, respectively, while the median was 9 .

The level of knowledge of the pharmacists surveyed was low (22.81\%), insufficient $(14.4 \%)$, medium $(50 \%)$ and good (13.16\%). Only 39 pharmacists $(34.21 \%)$ had received training in the management of diabetes. The average time of the last training was $33.76 \pm 24.6$ months with extremes of 6 months to 106 months. The training of pharmacists was provided by the medical representatives $(66.66 \%)$ the academics (26.67\%) and the ministry of supervision (6.67\%).

\subsubsection{Attitudes}

Feelings in front of a diabetic patient were need for help (68.42\%), compassion (42.11\%), anxiety (31.58\%), fear (21.93\%), and sadness (11, 40\%). Of 114 , only 56 pharmacists (49.12\%) cited both need for help and compassion.

More than $84.68 \%$ of community pharmacists felt that their knowledge of diabetes was insufficient, and the main reasons were: the unavailability of documentary sites and the lack of continuing education.

\subsubsection{Practices}

Of the 114 pharmacists, $57 \%(n=65)$ say that they test for diabetes in their pharmacy on the basis of capillary blood glucose. In a suspected case the advice of hygiene and dietetics (76.15\%) and the reference to the hospital (94.41\%) were the most cited gestures. Dialogue with diabetic patients was impossible for 26 (22.81\%) pharmacists and the reasons given were lack of time $(53.85 \%)$, space (11.53\%) and insufficient knowledge about diabetes (34.62\%).

\subsection{Analytical Part}

The level of knowledge was higher among pharmacists aged 40 and over ( $p=$ $0.69)$, there was no difference between men and women $(p=0.84)$ on the level of knowledge. The high rank (assistant and incumbent) $(p=0.24)$ and the experience greater than 5 years $(p=0.13)$ of exercise were associated with a good level of knowledge.

Table 2. Distribution of pharmacists according to the substitution modalities of oral anti diabetic (OAD), Dakar, Senegal, $2017(N=89)$.

\begin{tabular}{ccc}
\hline $\begin{array}{c}\text { Criteria for substitution of } \\
\text { an oral antidiabetic drug with another }\end{array}$ & Absolute frequency $(n)$ & Relative frequency (\%) \\
\hline Same molecule & 88 & 98.88 \\
Same dosage & 78 & 87.64 \\
Same action time & 41 & 46.07 \\
Same therapeutic class & 35 & 39.33 \\
Same treatment as the previous one & 15 & 16.85 \\
\hline
\end{tabular}


The good level of knowledge was more found in the subjects after 40 years, the female sex, the assistants and holders, after 5 years of professional experience. But there is no significance.

\section{Discussion}

In our study, the mean age was 33.90 years $( \pm 9.74)$ and nearly $80 \%$ of the pharmacists surveyed were under 40 years old. Pharmacists were mostly assistants with less than five years of professional experience.

In a study conducted by GUEYE A. with sixty pharmacists practicing in the regions of Dakar and Thies, shows that the majority of pharmacists were over 40 years old [9]. This contradiction could be due to the difference in sample sizes.

These results reflect low participation of regular pharmacists in the surveys. The study of GUEYE A. seems to confirm this situation. It shows that one in three attendees attend their pharmacy less than six days a week [9]. In addition, $57.9 \%$ of these pharmacists are present in their dispensary less than 7 hours a day [9]. However, their presence represents a great opportunity not only to pass on their knowledge to the assistants but also to enrich the surveys with their experiences. These teaching and researcher functions are strongly recommended by the WHO and the International Pharmaceutical Federation in order to optimize patient care and the accessibility of reliable information [10].

\subsection{The Knowledge}

The level of knowledge of half of the pharmacists was average. The good level was only observed at $13.16 \%$. A lower proportion was found in Nepal [11]. A study conducted in Qatar had also shown a low to moderate level of knowledge among a large proportion of pharmacists [12].

In addition, pharmacists' knowledge was not related to any socio-demographic characteristics. This lack of a statistically significant link could partly be explained by the small size of our sample on the one hand, and the absence of a continuing education program aimed at pharmacists, on the other hand. These results clearly indicate that building the capacity of community pharmacists in the prevention, management and management of diabetes remains a priority.

\subsection{The Attitude}

Empathy, one of the major skills to develop for the pharmacist, allows the patient to feel valued giving important information about her illness and her concerns [12]. In our study, $68.42 \%$ and $42.11 \%$ of pharmacists reported having a need for help and compassion in front of a diabetic patient respectively. This attitude allows the pharmacist to make decisions and assume her leadership position [10]. Thus, it can lead the patient to follow his diet, to respect his appointments at his GP and to have a better self-monitoring glycemic [13].

However, anxiety, fear and sadness were also the feelings listed by $31.58 \%$, 
$21.93 \%$ and $11.40 \%$ of pharmacists respectively. These emotional components felt by the pharmacist could be an obstacle to an exchange of information between the pharmacist and the patient. Many (53.2\%) were pharmacists who were struggling with some patient questions. But also can be explained by the lack of solid knowledge and stigma of the disease.

The pharmacist's role has evolved over the last forty years.

The role of the pharmacist has evolved over the last forty years. In the concept of "seven-star pharmacist", communication is identified as a new function of the pharmacist [10]. Beyond the patient, the pharmacist can communicate with his entourage of the diabetic patient. Our study revealed the awareness of this new function by all the pharmacists interviewed. This represents an opportunity for them to involve families more in educating diabetic patients to improve treatment adherence and quality of life.

However, the prerequisite for performing this function is the acquisition by the community pharmacist of solid knowledge and skills in communication techniques [10].

Nearly $85 \%$ of pharmacists felt that their knowledge of diabetes was inadequate. This has been reflected in all the pharmacists interviewed by a desire for training. This attitude demonstrates the awareness of the pharmacist in the management of diabetes. It is in keeping with the concept of "seven-star pharmacist" introduced by WHO and adopted by the International Pharmaceutical Federation (IDF). According to this concept, teaching in the faculties of pharmacy is not enough to cover all pharmacists' needs in terms of knowledge. Therefore, maintaining the level of knowledge and skills requires regular updating through continuous training [10].

\subsection{Practice}

The results of our survey revealed that $58.56 \%$ of pharmacists practice diabetes screening in their pharmacy. This proportion varies from one country to another. It was estimated at $41.2 \%$ and $67.5 \%$ respectively in Ethiopia [14] and Nigeria [15]. The involvement of pharmacists in diabetes screening is justified by the proximity to the population. Worldwide, $84.5 \%$ of people with diabetes are undiagnosed [2]. This situation shows that under-diagnosis of diabetes remains a major problem. Through early detection offers to patients by the pharmacist can play a major role in reducing under-screening. In Thailand, the pharmacist's contribution to diabetes screening is widely demonstrated [16]. The screening practice will allow them to identify and convince people at risk for a more accurate diagnosis. The topics to which the pharmacist may pay particular attention are, among others, the following [17]: Subject over the age of 45, overweight subject, topic treated for high blood pressure.

In this study, most pharmacists knew the diagnostic criteria for fasting blood glucose. This explains the practice of taking blood glucose, which is the recommended method of measurement in primary health care services in low-resource 
countries [14]. On the other hand, the diagnosis with the blood glucose at random is little known and constitutes the situation most encountered in the region of Dakar. This shows that there is still a need to strengthen the knowledge of pharmacists on all diagnostic criteria for diabetes to give credibility to the practice of pharmacy screening. In addition, $15.38 \%$ of pharmacists measured blood pressure at the same time as the blood glucose test. However, our investigation did not demonstrate calibration measures, management of glycemic readers and the practice of urinary control. A study conducted in France [18] revealed that pharmacists carry out this check under the following conditions: a doubt about the functioning of an insulin pump, the suspicion of a hyperglycemia, the existence of signs warning of a coma acid-ketotic or suggestive signs.

This practice of urinary control in pharmacies could be relevant in that it represents assistance in emergency decision-making in type 1 and some type 2 intercurrent states. It will also enable pharmacists to expand their service offerings. But further studies would be needed to assess its feasibility in pharmacy pharmacies in Senegal. The reference in a diabetes management structure must be in front of a suspected case of diabetes. During our survey this practice was adopted by the majority (94.41\%), $76.15 \%$ of them advised on the measures hygienes-dietary before referring against $18.26 \%$ who called the doctor.

The medical prescription of insulin and OAD or on presentation of the medication box was practiced by the majority of pharmacists. This is justified by the proximity of the pharmacist with the customers.

The presentation of an order will allow the pharmacist to appreciate the diligence of the patient at the appointment. It is also a good time to re-explain the dosages. However, only one pharmacist said advising insulin pharmacy.

\section{Conclusion}

Diabetes is a chronic disease that has become a major public health problem. Sub-Saharan Africa, characterized by poverty, poor infrastructure, and poor health care staff and changing eating habits, faces the burden of diabetes mellitus. The pharmacist, a health professional who specializes in medication, is the preferred contact for patients because of the proximity of accessibility. It plays a fundamental role in this path of diabetic patient care, especially in the prevention, screening and social management of chronic diseases. Our study shows that pharmacy pharmacists are relatively young, with a low level of knowledge but a good attitude and practices. Continuous knowledge building is the strong link for better management of diabetic patients.

\section{Conflicts of Interest}

The authors declare no conflicts of interest regarding the publication of this paper.

\section{References}

[1] Defronzo, R.A., Ferrannini, E., Zimmet, P. and Alberti, K.G.M.M. (2015) Interna- 
tional Textbook of Diabetes Mellitus. 4th Edition, Wiley-Blackwell, Oxford, 1240 p. https://doi.org/10.1002/9781118387658

[2] IDF (2017) Atlas du diabète de la FID. 8ème Édition, 52-61.

[3] Halimi, S. (1993) Données épidémiologiques sur le diabète de type 2 (DNID). Rapport, Grenoble, 6 p.

[4] Mathers, C.D. and Loncar, D. (2006) Projections of Global Mortality and Burden of Disease from 2002 to 2030. PLOS Medicine, 3, 442.

https://doi.org/10.1371/journal.pmed.0030442

[5] Ministère de la santé et de l'action sociale MSAS (2018) Enquête nationale sur les facteurs des risques des maladies non transmissibles, STEP Sénégal 2015, rapport préliminaires: Indicateurs clés.

[6] ANSD (2014) Enquête démographique et de santé continue au Sénégal (EDS-Continue), Situation Economique et Sociale de la Région de Dakar, édition 2014. In: ANSD, Ed., Agencenationale de la statistique et de la démographie (ANSD). http://www.ansd.sn/ressources/ses/chapitres/4-sante-hygiene-publidakar2014.pdf

[7] Boudreau, G. (1990) Le changement de comportement en général. Université de Moncton. http://www8.umoncton.ca/littoral-vie/ecosage/Gaston2.rtf

[8] José, E.M. and Oudou, N. (2013) L'Enquête CAP (Connaissances, Attitudes, Pratiques) en Recherche Médicale. Health Sciences and Diseases, 14.

[9] Gueye, A. (2016) Analyse de données sur le respect de l'exercice de la profession pharmaceutique en officine dans la région de Dakar et de Thiès. Thèse en pharmacie, Université Dakar, Dakar, 88 p.

[10] Organisation mondiale de la Santé (2006) FIP. Elargir la pratique pharmaceutique. Recentrer les soins sur les patients. Manuel-Edition 2006. WHO/PSM/PAR/2006.5.

[11] Shrestha, M., Maharjan, R., Prajapati, A., Ghimire, S., Shrestha, N. and Banstola, A. (2015) Assessment of Knowledge and Practice of Community Pharmacy Personnel on Diabetes Mellitus Management in Kathmandu District: A Cross Sectional Descriptive Study. Journal of Diabetes \& Metabolic Disorders, 14, 71. https://doi.org/10.1186/s40200-015-0205-7

[12] El Hajj, M.S., Abu Yousef, S.E., Basri, M.A., et al. (2018) Diabetes Care in Qatar: A Survey of Pharmacists' Activities, Attitudes and Knowledge. International Journal of Clinical Pharmacy, 40, 84-93. https://doi.org/10.1007/s11096-017-0562-Z

[13] Kusum, P. (2010) Comment optimiser la dynamique relationnelle patient-pharmacien pour assurer une alliance thérapeutique. These pour le Diplôme d'Etat de Docteur en Pharmacie, Universite de Bourgogne, Dijon.

[14] Erku, D.A. and Mersha, A.G. (2017) Involvement of Community Pharmacists in Public Health Priorities: A Multi-Center Descriptive Survey in Ethiopia. PLoS ONE, 12, e0180943. https://doi.org/10.1371/journal.pone.0180943

[15] Offu, O., Anetoh, M., Okonta, M. and Ekwunife, O. (2015) Engaging Nigerian Community Pharmacists in Public Health Programs: Assessment of Their Knowledge, Attitude and Practice in Enugu Metropolis. Journal of Pharmaceutical Policy and Practice, 8, 27. https://doi.org/10.1186/s40545-015-0048-0

[16] Asayut, N., Sookaneknun, P., Chaiyasong, S. and Saramunee, K. (2018) Outcomes, Costs and Stakeholders' Perspectives Associated with the Incorporation of Community Pharmacy Services into the National Health Insurance System in Thailand: A Systematic Review. International Journal of Pharmacy Practice, 26, 16-27. https://doi.org/10.1111/ijpp.12385

[17] Pacreau, L. (2014) Le rôle du pharmacien d'officine dans la prise en charge d'un pa- 
tient diabétique de type 2. Th pharma. Université de Limoges, Limoges, 157 p.

[18] Badia, M. (2011) Dépistage du diabète de type 2 par les pharmaciens d'officine: Enquête descriptive sur la pratique auprès de leurs patients et résultats de plusieurs campagnes de dépistage dans les officines lorraines en 2007, 2008 et 2010. Th Pharma. Universite henri Poincare, 156 p. 